\title{
Effects of antler breakage on mating behavior in male tule elk (Cervus elaphus nannodes)
}

\author{
Heather E. Johnson • Vernon C. Bleich •
}

Paul R. Krausman • John L. Koprowski

Published online: 1 November 2006

(C) Springer-Verlag 2006

The online version of the original article can be found at http://dx.doi. org/10.1007/s10344-006-0060-4.

H. E. Johnson $(\bowtie) \cdot$ V. C. Bleich

Sierra Nevada Bighorn Sheep Recovery Program,

California Department of Fish and Game,

407 West Line Street,

Bishop, CA 93514, USA

e-mail: hjohnson@dfg.ca.gov

P. R. Krausman · J. L. Koprowski

School of Natural Resources, The University of Arizona,

325 Biological Sciences East,

Tucson, AZ 85721, USA
In the electronic version of this paper, Figs. 1 and 2 were switched. They appear correct below and are correct in the print version. 
Fig. 1 Photos of antler breakage on male tule elk, Owens Valley, California
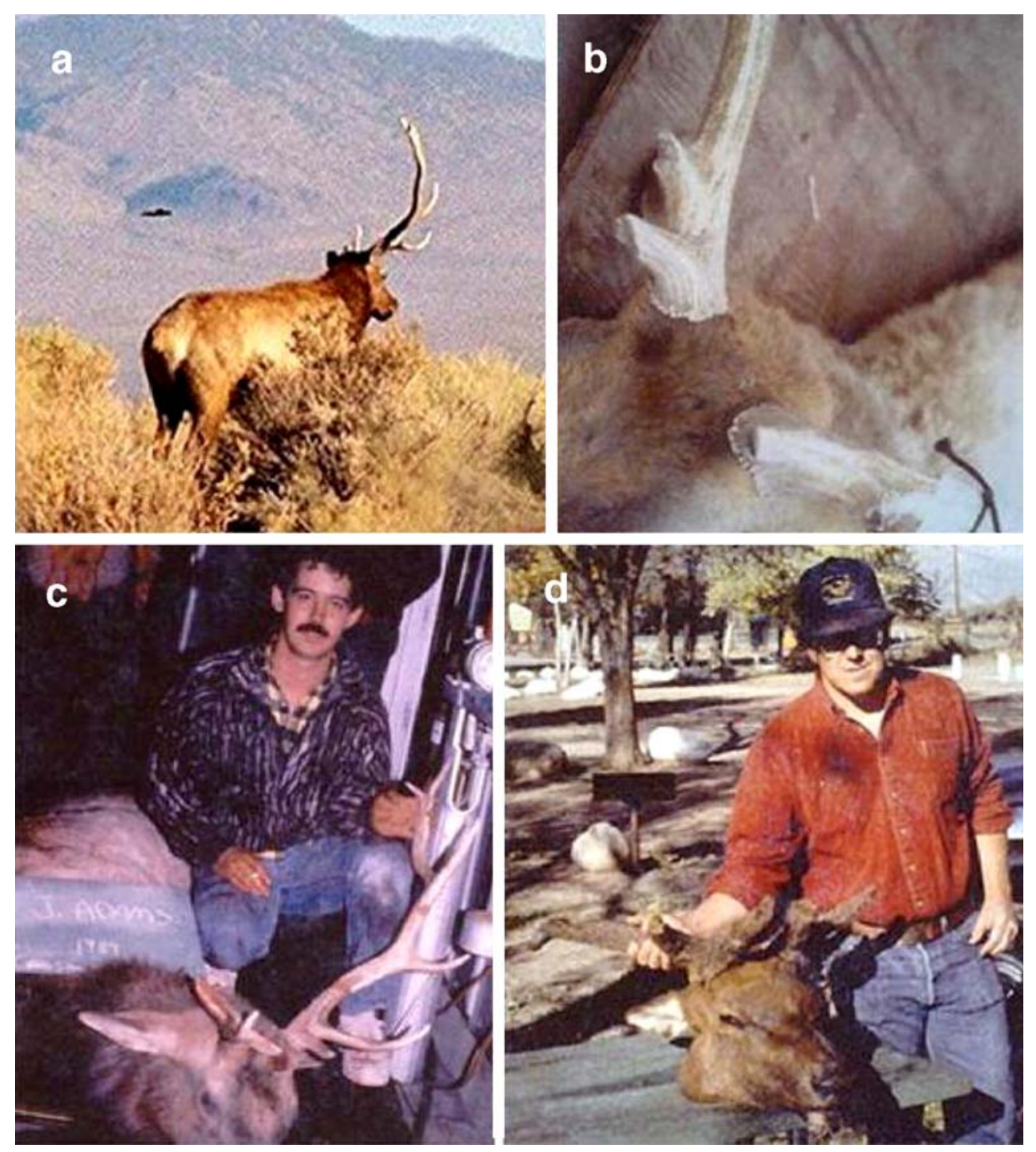
Fig. 2 Number of antler tines of uniquely identifiable male tule elk $(n=112)$ possessed at the beginning of rut (pre-breakage) and at the end of rut (postbreakage), Owens Valley, California, 2002-2003

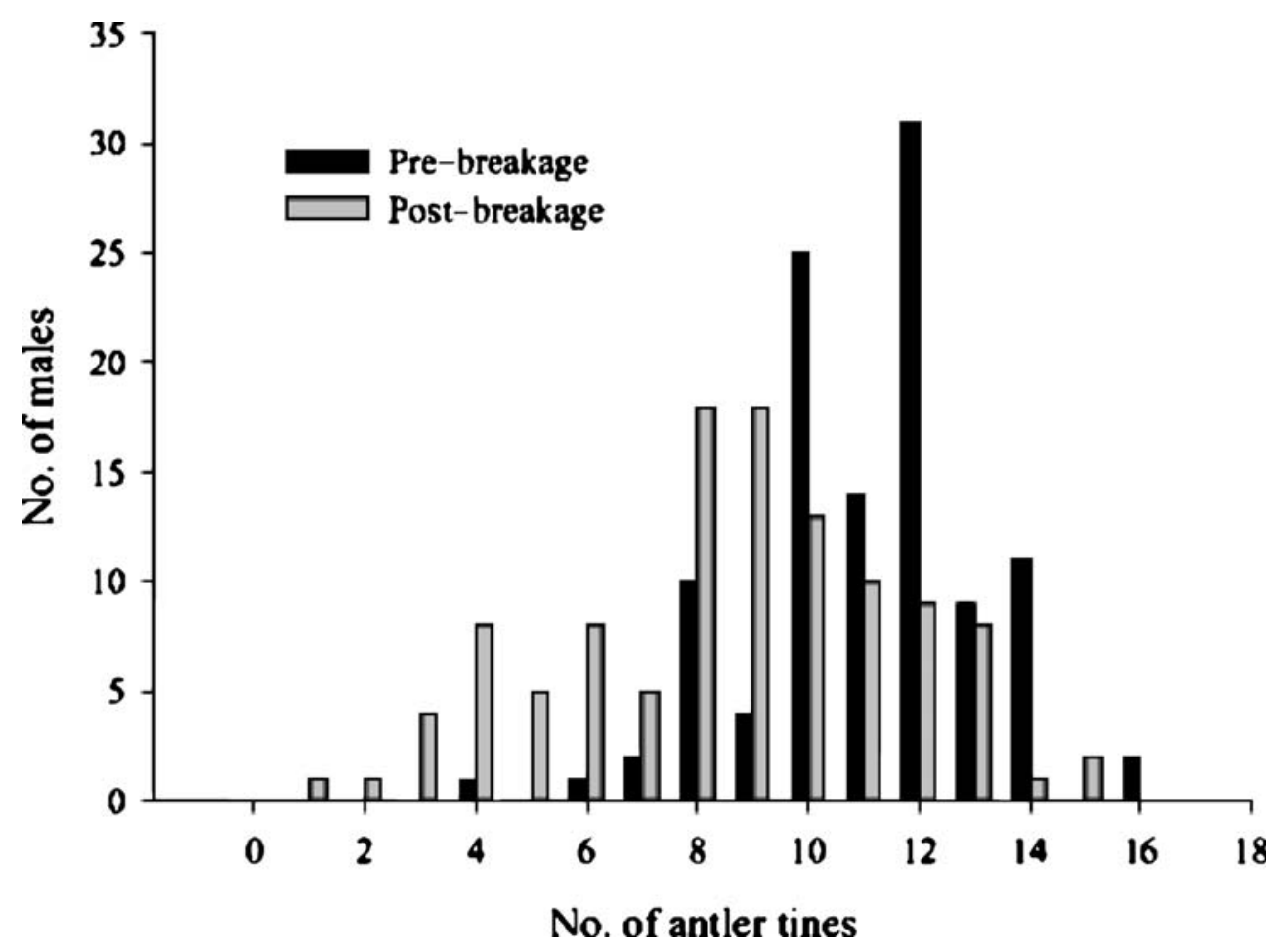

